\title{
Language Weaver Arabic->English MT
}

\author{
Daniel MARCU, Alex FRASER, William WONG, Kevin KNIGHT \\ Language Weaver, Inc. \\ 4640 Admiralty Way, Suite 1210 \\ Marina del Rey, CA, USA, 90292 \\ \{marcu,afraser,wong,knight $\} @$ languageweaver.com
}

\begin{abstract}
This presentation is primarily a demonstration of a working statistical machine translation system which translates Modern Standard Arabic into English.
\end{abstract}

\section{Overview}

Language Weaver has produced a highperformance statistical Arabic-to-English machine translation system, based on research work conducted at the University of Southern California, Information Sciences Institute (USC/ISI). Getting resource-unlimited laboratory systems to run in real time, on a typical desktop Windows machine, is among Language Weaver's contributions. The system is designed to provide broad general coverage of Arabic news, and is currently used at various sites within the U.S. Government.
The Arabic->English translation system to be demonstrated has been prepared in versions that require 1 or $2 \mathrm{~GB}$ of RAM, and run on a $1.5 \mathrm{GHz}$ or faster processor and translates at a minimum rate of 500 words per minute. The system includes an option to trade off speed for quality in the translation process allowing users to select the fastest possible gisting-quality output, or the best possible translation quality for each sentence.

\section{Demonstration}

The translation system will be demonstrated on current news, and possibly other postings from Internet, or other files:

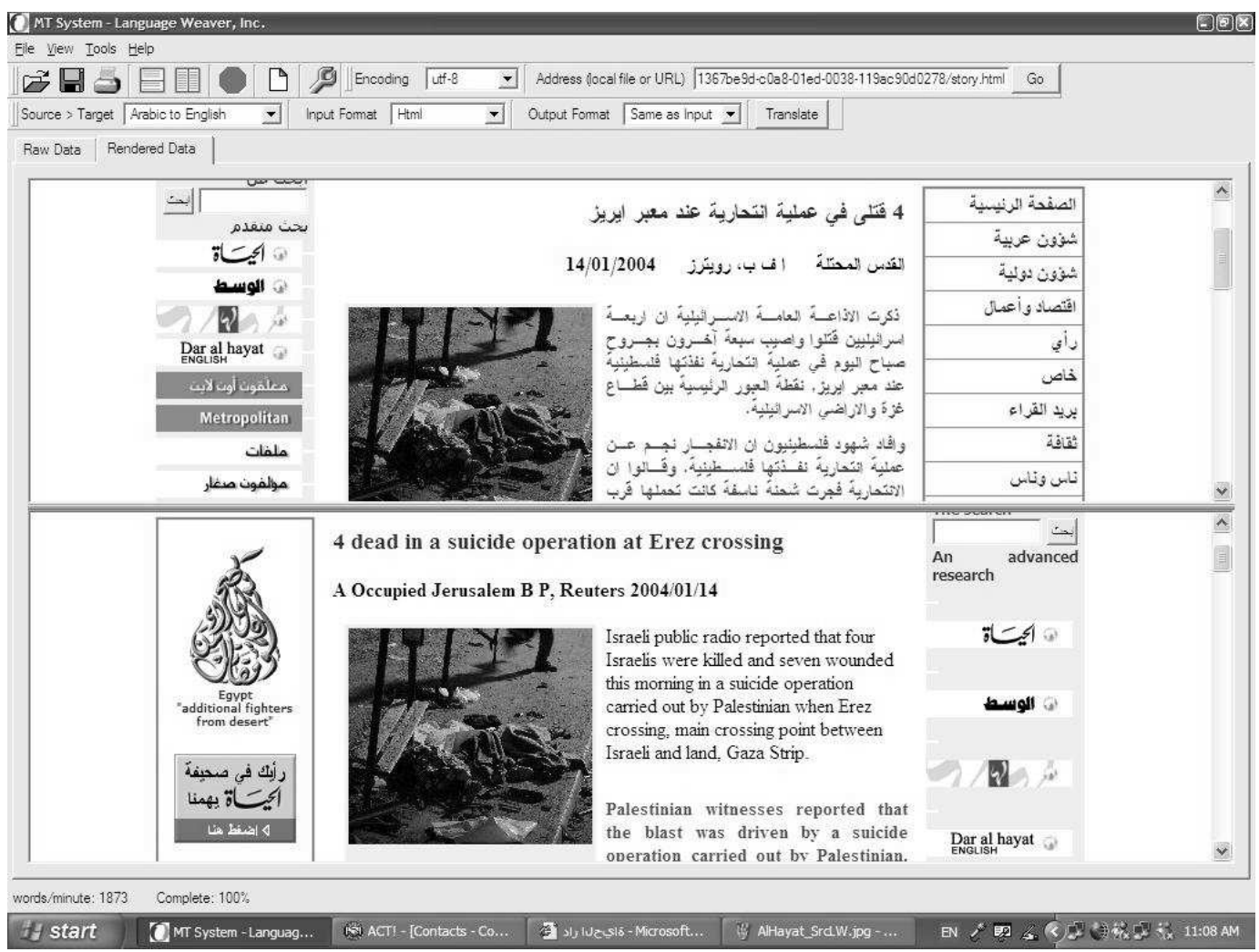

